\title{
Analysis of Thermo-Electric Field in Steel Strip with Multiple Cracks
}

\author{
Thomas Jin-Chee Liu ${ }^{*}$, Ji-Fu Tseng, Po-Heng Chen \\ Department of Mechanical Engineering, Ming Chi University of Technology, Taishan, Taipei, Taiwan \\ *Corresponding Author: jinchee@mail.mcut.edu.tw
}

\begin{abstract}
This paper presents a primary study and its results of the thermo-electric field in a steel strip with multiple cracks under the electric current. As a result, the hot spot exists at the crack tip due to the Joule heating effect. When the gap between two cracks is relatively small, the hot spots at the crack tips may not be obvious. It may disturb the crack detection.
\end{abstract}

Keywords: crack, thermo-electric, Joule heating, thermal image, finite element analysis.

\section{Introduction}

When a cracked metal component is subjected to the electric current, a hot spot can be produced at the crack tip due to the electric current density concentration and Joule heating effect. Fig. 1 shows this phenomenon.

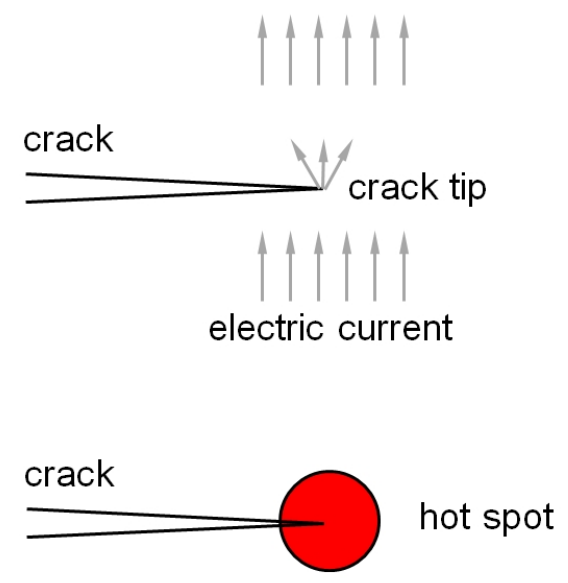

Fig. 1. Hot spot at crack tip.

In the past studies ${ }^{(1-5)}$, the results demonstrated that a local hot spot exists at the crack tip under the electric current. This phenomenon can be applied on the thermal sensing technique for detecting cracks or fractures in metal components. The induction heating method is usually used for the crack detection. However, the steady electric current is adopted for the crack detection in this paper.

As a primary study, the research of this paper investigates the thermo-electric field in a steel strip with multiple cracks under the electric current. The research methods include the finite element analysis and thermal imaging experiment. Especially, the effect of the gap between two cracks is investigated.

\section{Problem}

In Fig. 2, it shows the strip geometry and electric load of this research. The thin strip has the dimensions $W \times L$ and thickness $e$. There are five edge cracks. The crack length and gap are denoted as $a$ and $b$, respectively. The strip is subjected to a direct current (DC) $I_{0}$. The material type of the strip is the SUS 304 stainless steel. In Table 1, it lists the material data of the SUS 304 stainless steel ${ }^{(6)}$. The thermal conductivity and electric resistivity are temperature-dependent.

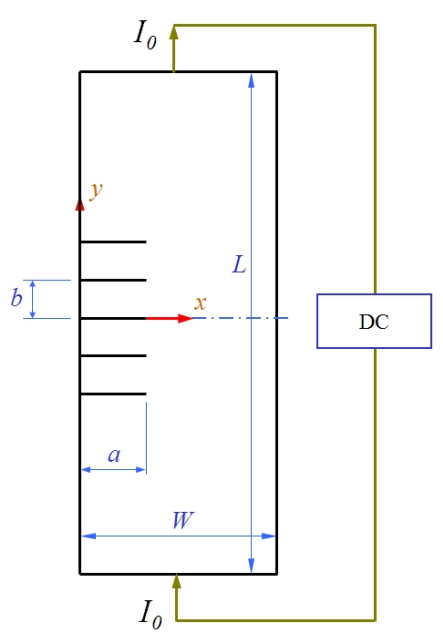

Fig. 2. Strip geometry and external load. 
Table 1. Material data of SUS 304 steel $^{(6)}$.

\begin{tabular}{ll}
\hline density & $8000 \mathrm{~kg} / \mathrm{m}^{3}$ \\
thermal conductivity & $16.2 \mathrm{~W} / \mathrm{m}-\mathrm{K} @ 0 \sim 100{ }^{\circ} \mathrm{C}$ \\
& $21.5 \mathrm{~W} / \mathrm{m}-\mathrm{K} @ 500{ }^{\circ} \mathrm{C}$ \\
& $500 \mathrm{~J} / \mathrm{kg}-\mathrm{K}$ \\
specific heat & $7.2 * 10^{-7} \Omega-\mathrm{m} @ 20{ }^{\circ} \mathrm{C}$ \\
resistivity & $7.8 * 10^{-7} \Omega-\mathrm{m} @ 100{ }^{\circ} \mathrm{C}$ \\
& $8.6 * 10^{-7} \Omega-\mathrm{m} @ 200{ }^{\circ} \mathrm{C}$ \\
& $10 * 10^{-7} \Omega-\mathrm{m} @ 400{ }^{\circ} \mathrm{C}$ \\
& $11.6 * 10^{-7} \Omega-\mathrm{m} @ 650{ }^{\circ} \mathrm{C}$ \\
\hline
\end{tabular}

\section{Principles}

Four groups of equations describing the basic theory of this study are listed as follows ${ }^{(7-9)}$ :

$$
\begin{aligned}
& \mathbf{E}=-\nabla \phi, \quad \mathbf{J}=\frac{1}{\rho} \mathbf{E}, \quad \nabla \cdot \mathbf{J}=0 \\
& \mathbf{q}^{\prime \prime}=-k \nabla T, k \nabla^{2} T+\dot{q}=\beta C_{p} \frac{\partial T}{\partial t} \\
& \dot{q}=\rho|\mathbf{J}|^{2} \\
& {\left[\begin{array}{cc}
\mathbf{C}^{\mathbf{t}} & 0 \\
0 & 0
\end{array}\right]\left\{\begin{array}{c}
\dot{\mathbf{T}} \\
\dot{\mathbf{V}}
\end{array}\right\}+\left[\begin{array}{cc}
\mathbf{K}^{\mathbf{t}} & 0 \\
0 & \mathbf{K}^{\mathbf{v}}
\end{array}\right]\left\{\begin{array}{l}
\mathbf{T} \\
\mathbf{V}
\end{array}\right\}=\left\{\begin{array}{l}
\mathbf{Q} \\
\mathbf{I}
\end{array}\right\}}
\end{aligned}
$$

In Eq. (1), E, J, $\phi$ and $\rho$ are the electric field, electric current density, electric potential and resistivity, respectively. In Eqs. (2) and (3), $\mathbf{q}^{\prime \prime}, k, T, \dot{q}, \beta, C_{p}$ and $t$ are the heat flux, thermal conductivity, temperature, heat generation of Joule heating, mass density, specific heat and time, respectively. In Eq. (4), T, V, $\mathbf{Q}$ and $\mathbf{I}$ are the vector forms of the temperature, electric potential, heat flow rate and electric current, respectively. The material constant matrices $\mathbf{C}^{\mathbf{t}}, \mathbf{K}^{\mathbf{t}}$ and $\mathbf{K}^{\mathbf{v}}$ are the thermal specific heat, thermal conductivity and electric conductivity, respectively. The coupled heat flow matrix $\mathbf{Q}$ contains the effects of the thermal loading and Joule heating. Eq. (4) is a directly coupled nonlinear equation which is solved using the Newton-Raphson iterative method. Eqs. (1)-(4) will be solved using the finite element software ANSYS ${ }^{(9)}$.

\section{Methods of Research}

\subsection{Finite Element Analysis}

Fig. 3 shows the finite element model of ANSYS with the dimensions: $W=10 \mathrm{~mm}, L=240 \mathrm{~mm}, e=0.05 \mathrm{~mm}, a=5$ $\mathrm{mm}$ and $b=12 \mathrm{~mm}$. It is modeled by the SOLID226 element, i.e. the 20-node isoparametric solid element associated with the thermo-electric analysis. The crack tip region is modeled by the quarter-point elements for expressing the $r^{-1 / 2}$ singularity of the electric current density field.

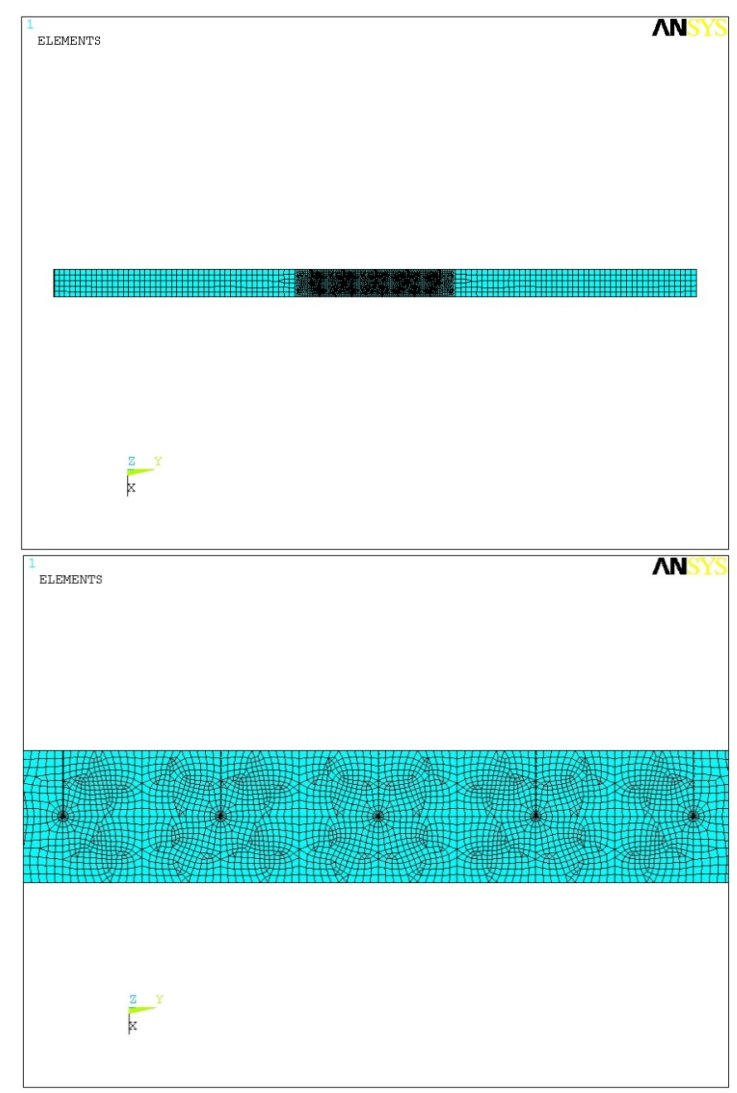

Fig. 3. Finite element model.

The following conditions are considered in the finite element analysis:

(1) Three-dimensional analysis

(2) Thermo-electric coupled-field

(3) Transient heat transfer

(4) Convection on air/strip interface

(5) Steady electric current (DC current)

(6) Temperature-dependent material data

(7) Electric insulation on crack surface

\subsection{Thermal Imaging Experiment}

Fig. 4 shows the experimental facilities of this study. The SUS 304 steel strip is connected to the DC power supplier. Due to the Joule heating effect, the strip is heated. 
The thermal image camera (designed by FLIR Co.) is used to capture the surface temperature field of the strip. The strip is shown in Fig. 5. It has five edge cracks in the central region. To capture the surface temperature image, the strip must be coated by the black paint.

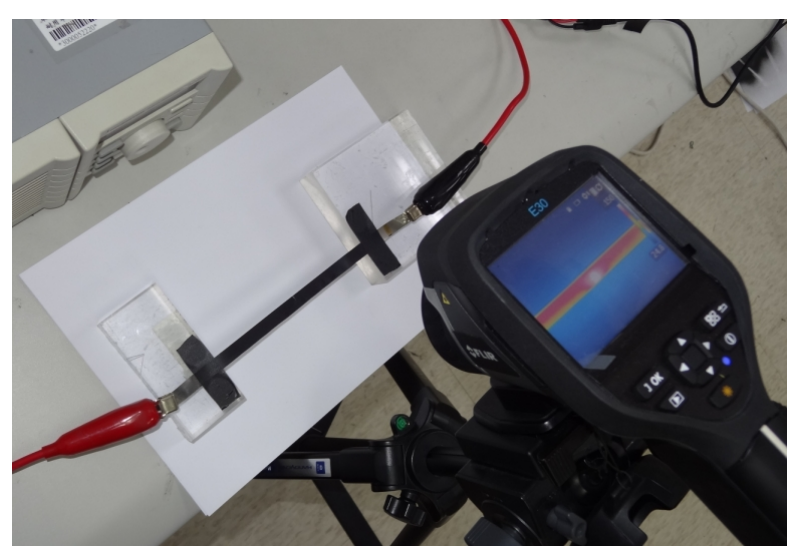

Fig. 4. Experimental facilities.

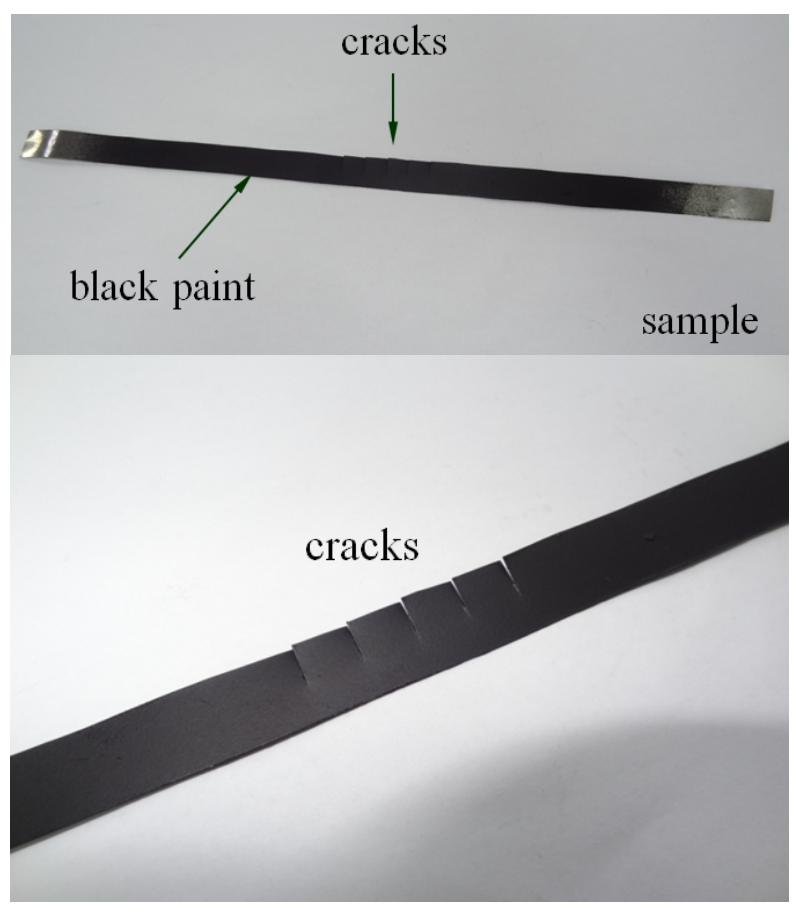

Fig. 5. Steel strip.

\section{Results and Discussions}

\section{$5.1 \quad$ Joule Heating}

The strip has the following dimensions: $W=10 \mathrm{~mm}$, $L=240 \mathrm{~mm}, e=0.05 \mathrm{~mm}, a=5 \mathrm{~mm}$ and $b=12 \mathrm{~mm}$. The initial and ambient temperature are $26^{\circ} \mathrm{C}$. The electric current $I_{0}=$ $5 \mathrm{~A}$ is applied on the strip.
In the finite element analysis, the natural convection coefficient applied on the strip surfaces is $21 \mathrm{~W} / \mathrm{m}^{2}-\mathrm{K}$. Using the finite element analysis, Fig. 6 shows the electric current density at $60 \mathrm{~s}$. There is a local concentration of the electric current density near the crack tip. Five cracks have the same phenomena. Similar to the elastic stress field, the electric current density also has the $r^{-1 / 2}$ singularity at the crack tip ${ }^{(2)}$. In Fig.7, it can be seen that the Joule heating effect causes a high temperature area (hot spot) around the crack tip.

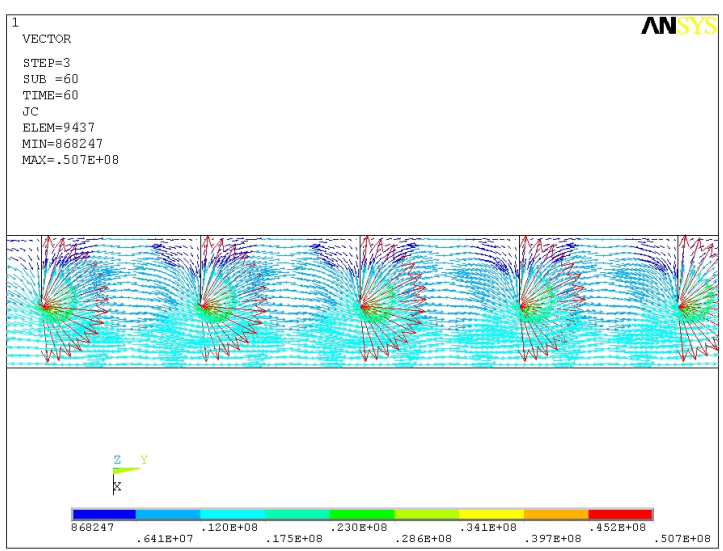

Fig. 6. Electric current density $\left(b=12 \mathrm{~mm}\right.$, units: $\left.\mathrm{A} / \mathrm{m}^{2}\right)$.

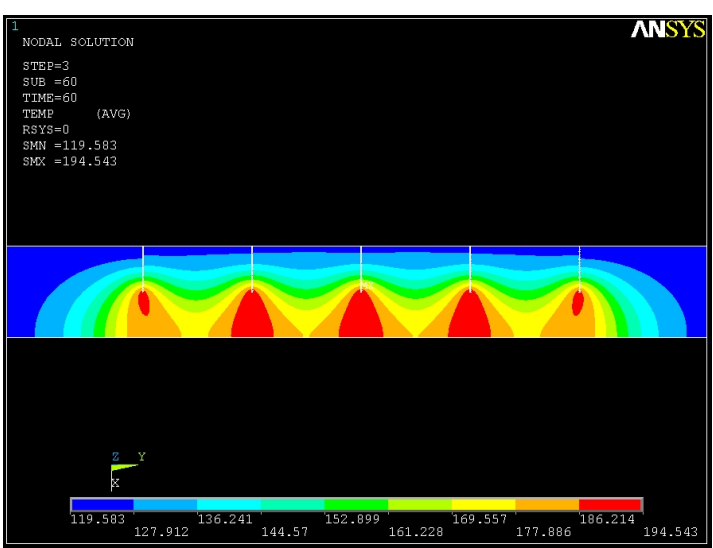

Fig. 7. Temperature field $\left(b=12 \mathrm{~mm}\right.$, units: $\left.{ }^{\circ} \mathrm{C}\right)$.

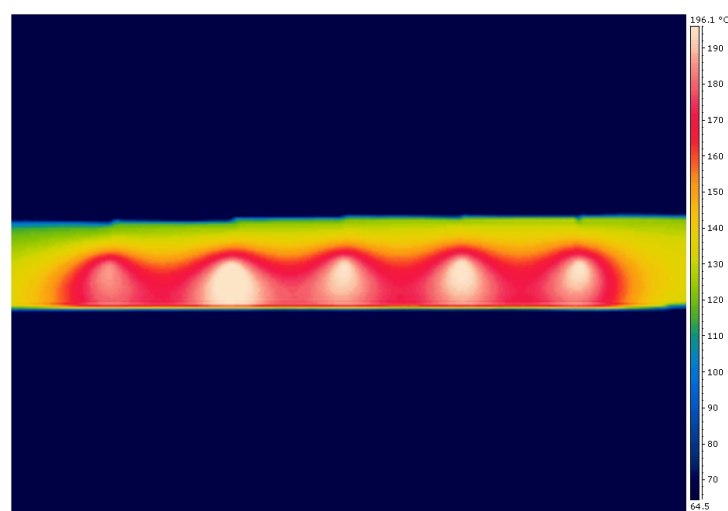

Fig. 8. Thermal image $\left(b=12 \mathrm{~mm}\right.$, units: $\left.{ }^{\circ} \mathrm{C}\right)$. 
The thermal camera is also used to investigate the temperature field on the steel strip. In the experiment, the strip geometry is the same as the finite element model. Fig. 8 shows the thermal image of the steel strip with five cracks. There are local hot spots around the crack tips.

\subsection{Effect of Gap between Two Cracks}

The gap $b$ is changed from $12 \mathrm{~mm}$ to $5 \mathrm{~mm}$ in this section. From the finite element results, Figs. 9 and 10 show the electric current density and temperature field at 60 s. In addition, Fig. 11 shows the thermal image of the steel strip.

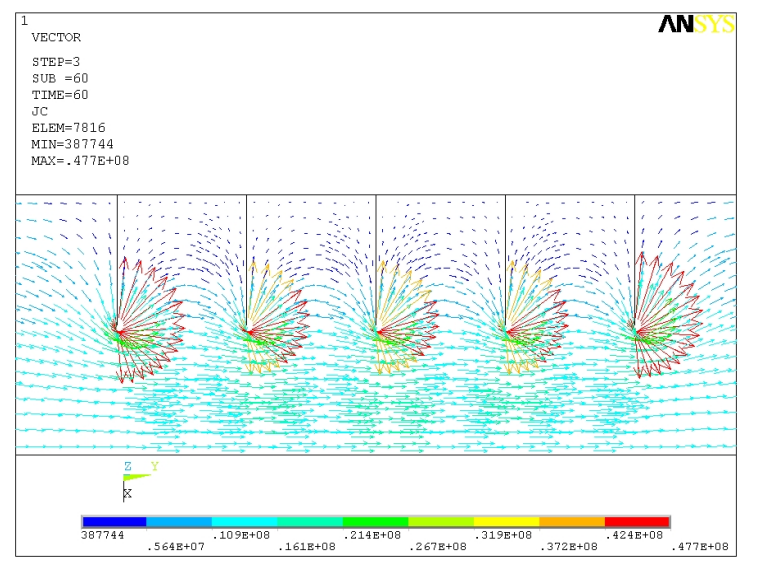

Fig. 9. Electric current density ( $b=5 \mathrm{~mm}$, units: $\left.\mathrm{A} / \mathrm{m}^{2}\right)$.

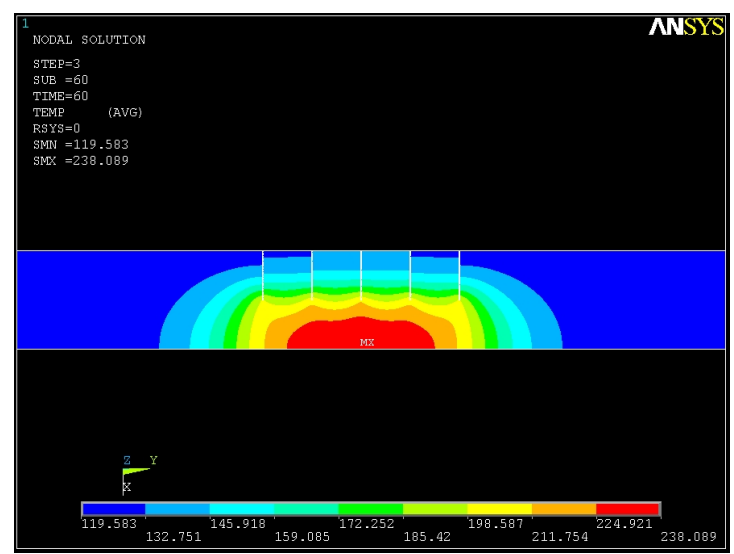

Fig. 10. Temperature field $\left(b=5 \mathrm{~mm}\right.$, units: $\left.{ }^{\circ} \mathrm{C}\right)$.

In Figs. 10 and 11, the maximum temperature occurs on the edge of the strip. The local hot spots at the crack tips are not obvious. It may disturb the crack detection.

When the gap between two cracks is relatively small, another large electric concentration occurs near the strip edge. This phenomenon is similar to the fluid problem. Due to Joule heating, it also makes a hot region near the strip edge.

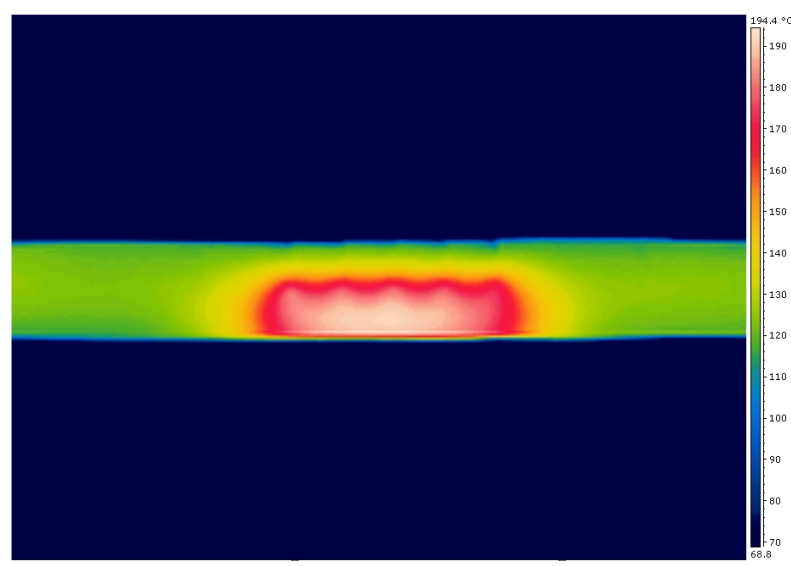

Fig. 11. Thermal image $\left(b=5 \mathrm{~mm}\right.$, units: $\left.{ }^{\circ} \mathrm{C}\right)$.

\section{Conclusions}

The finite element analysis and thermal imaging experiment are used to investigate the thermo-electric field of the strip. When the gap between two cracks is relatively small, the local hot spots at the crack tips are not obvious. It may disturb the crack detection.

\section{Acknowledgment}

The authors would like to thank the Ministry of Science and Technology in Taiwan for the financial support under contract numbers NSC 101-2221-E-131-011 and MOST 103-2221-E-131-015. Also, the authors appreciate the support of the research project 103-AcademicResearchE-02 of Ming Chi University of Technology.

\section{References}

(1) V.Z. Parton and B.A. Kudryavtsev: Electromagnetoelasticity, Gordon and Breach, New York, 1988

(2) G.X. Cai and F.G. Yuan: "Electric Current-Induced Stresses at the Crack Tip in Conductors", International Journal of Fracture, Vol. 96, pp. 279, 1999

(3) Y.M. Fu, X.Z. Bai, G.Y. Qiao, Y.D. Hu, and J.Y. Luan: "Technique for Producing Crack Arrest by Electromagnetic Heating", Materials Science and Technology, Vol. 17, pp. 1653, 2001

(4) Z. Qin, L. Librescu and D. Hasanyan: "Joule Heating 
and Its Implications on Crack Detection/Arrest in Electrically Conductive Circular Cylindrical Shells", Journal of Thermal Stresses, Vol. 30, pp. 623, 2007

(5) T.J.C. Liu: "Finite Element Modeling of Melting Crack Tip under Thermo-Electric Joule Heating", Engineering Fracture Mechanics, Vol. 78, pp. 666, 2011

(6) Online Materials Information Resource - MatWeb, http://matweb.com/

(7) D.K. Cheng: Field and Wave Electromagnetics, Addison-Wesley, MA, 1983

(8) F.P. Incropera and D.P. DeWitt: Fundamentals of Heat and Mass Transfer, Fifth Ed., John Wiley \& Sons, USA, 2002

(9) ANSYS HTML Online Documentation, SAS IP, Inc., USA, 2005 